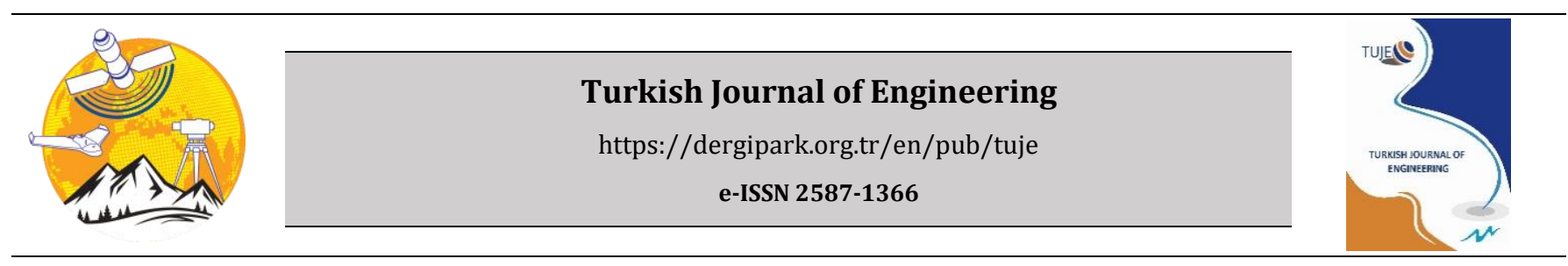

\title{
Image processing-based realization of servo motor control on a Cartesian Robot with Rexroth PLC
}

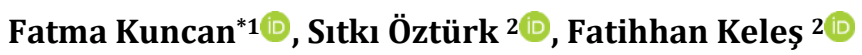 \\ ${ }^{1}$ Siirt University, Faculty of Engineering, Department of Computer Engineering, Siirt, Turkey \\ ${ }^{2}$ Kocaeli University, Faculty of Engineering, Department of Electronics and Communication Engineering, Kocaeli, Turkey
}

\author{
Keywords \\ Image Processing \\ Servo Motor Control \\ Cartesian Robot \\ Rexroth PLC
}

\begin{abstract}
The aim of this study was to separate the objects, whose position was determined using Rexroth PLC on a workbench, and bring them to different locations. Position control of synchronous motors with PLC was done with coordinates obtained by image processing. A real-time Gantry robot was set up for the study. An image taken with the camera connected to Gantry robot is transferred to the Matlab environment. The coordinate data obtained by processing the image are separated for the coordinates used, and the position control of the motors is provided. First, the image was changed to grayscale to apply image processing methods. Then, with the image processing formula, 'viscircles' has been applied to mark the detected circles. The obtained coordinates were transferred to IndraWorks PLC to be used in the portal robot. Objects in the determined coordinates were moved to another coordinate with the help of the pneumatic system that integrated to Gantry Robot. The system has been tested for different conditions. As a result of studies, it has been observed that both the image processing method and the system work simultaneously with high accuracy. It is thought that the study can be used in many areas in the literature.
\end{abstract}

\section{INTRODUCTION}

In the technology movement that progresses with time and continues to accelerate, it is a necessity to solve the problems with fast and sharp methods. This requirement has played a major role in the transition of people to robotic systems, and we see that many industrial factories produce by using robots in their systems in this area. It has become essential that these systems should become widespread not only in the industrial sector but also in every stage of life such as education, health, military, and economy. In recent years, researchers have widely used robot, autonomous and image processing studies (Bakır et al. 2012; Çubukçu et al. 2015; Köse et al. 2019). One of the most important reasons for this increase is the transition to automation systems instead of people. Both researchers and industrial (industrial) practitioners have turned to automation and robotics in recent years (Horoz et al. 2013; Jose and Udupa 2021; Hu et al. 2021). This study, on the other hand, is a study of an autonomous system in which servo motors, one of the cornerstones of industrial motion, are controlled by PLCs. The applications made during the project process firstly start in the software part. The image taken with the camera is first processed in the MATLAB software program. Our goal is, find the coordinates of objects on a gantry robot workbench. In this study, the image processing functions of the 'Image Processing Toolbox' application are applied to the image. After the pixel coordinates are processed with functions containing the obtained image synchronization parameters, coordinate information in ' $\mathrm{mm}$ ' unit is obtained. Obtained coordinates are writed to data sequences in PLC. With many components such as variables, buttons, timers defined in the PLC program, movement is provided with logic operations in the program blocks. After the motion is provided, the necessary program blocks for system automation are written. Pneumatic piston is used to control movement in $\mathrm{z}$-axis. It is aimed to move the objects in the obtained coordinates to other coordinates with this pneumatic system. After the pneumatic system is activated, the autonomy is checked and the results are shared. The PLC used on the system belongs to BoschRexroth. The software of the study was IndraWorks software published by Bosch-Rexroth Company for PLC.

\footnotetext{
* Corresponding Author

*(fatmakuncan@siirt.edu.tr) ORCID ID 0000-0003-0712-6426

(sozturk@kocaeli.edu.tr) ORCID ID 0000-0003-3804-5581

(fatihkeles.41@gmail.com) ORCID ID 0000-0002-6375-5553
} Kuncan F, Öztürk S \& Keleş F (2022). Image processing-based realization of servo motor
control on a Cartesian Robot with Rexroth PLC. Turkish Journal of Engineering, 6(4), control on a Cartesian Robot with Rexroth PLC. Turkish Journal of Engineering, 6(4),
$320-326$ 


\section{SYSTEM COMPONENTS}

The Block Structure of the realized gantry robot is given in Figure 1. In this work, basically 3 main components were used to make the system the desired one. These are Servo motor, PLC, and Image Processing, respectively. First of all, these 3 components are explained in the article, then the general operation of the system will be discussed.

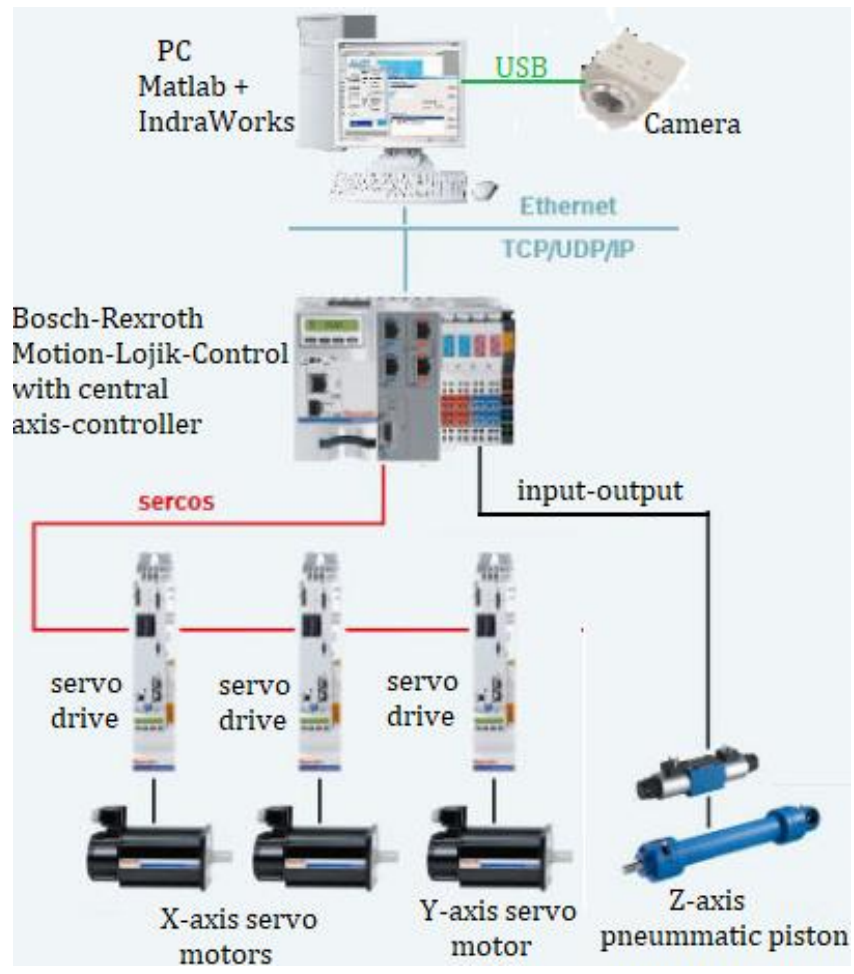

Figure 1. Block structure of the realized gantry robot

\subsection{Servo Motor}

Servo motors contain a DC motor that drives the motor. Apart from this motor, there is a gear mechanism, a potentiometer, and a motor driver circuit. The potentiometer measures the amount of rotation of the motor shaft. As the DC motor in the servo moves, the potentiometer rotates and the control circuit compares the position of the motor with the desired position and drives the motor. The servo motors used in the portal robot bench are shown in Figure 2.

\subsection{PLC}

PLC receives analog and digital information from the sensors or input devices it is connected to. The program written for the control of these data outputs is run and new output values are obtained based on the pre-programmed parameters. The output ports of the PLC are updated to control the system with the obtained analog and digital output values. This study generally constitutes the working principle of PLC. Briefly, a PLC first writes the data on the input port to the input data memory. Then the program written to control the system is run. Finally, analog and digital values in the output data memory are written to the output port. This cycle of the PLC starts when the PLC is RUN and continues its operation by repeating the cycle until it stops.

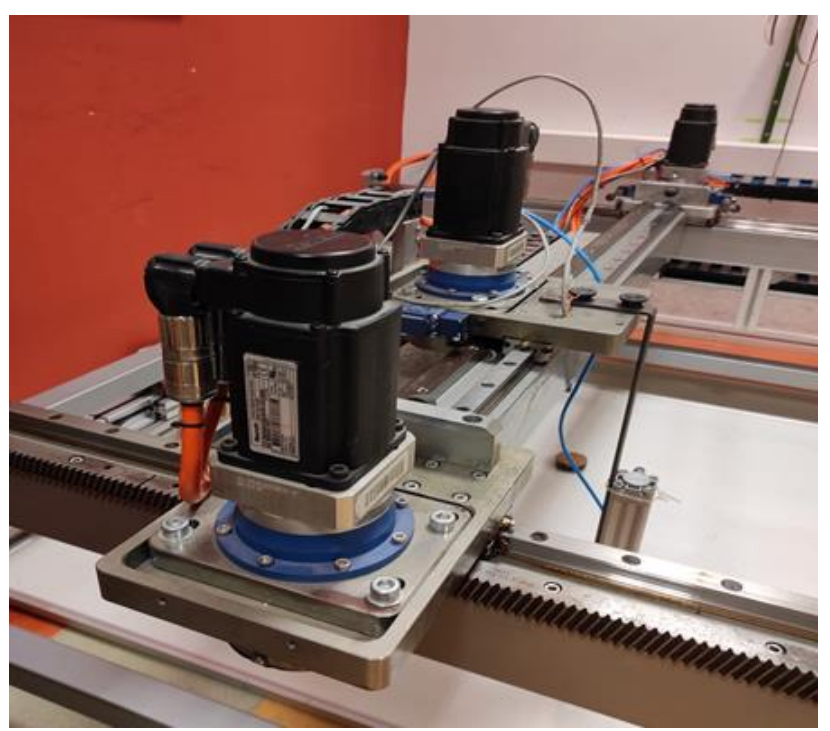

Figure 2. Servo motors used in gantry robot workbench

In this study, the control of the system and realtime operation are carried out by PLC to make the results obtained by the image processing method by the Matlab software. To carry out these operations, the necessary software work for the PLC must be done. The software made is written in the 'Drive Control' section, which is the sub-tab of the POU. This is where code diagrams are written through networks. These software studies have been carried out as the program progresses autonomously. For the motors to reach the desired position, all parameters must be defined in the PLC block.

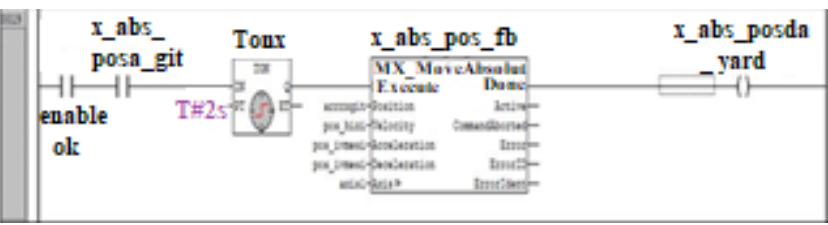

Figure 3. Defining the coordinates to the motion block

To access the detected objects, the $\mathrm{x}$ and $\mathrm{y}$ coordinates of the object must be pulled from the array sequentially. An ' $i$ ' variable is defined for this action. Objects are accessed sequentially with a for loop connected to the variable 'i'.

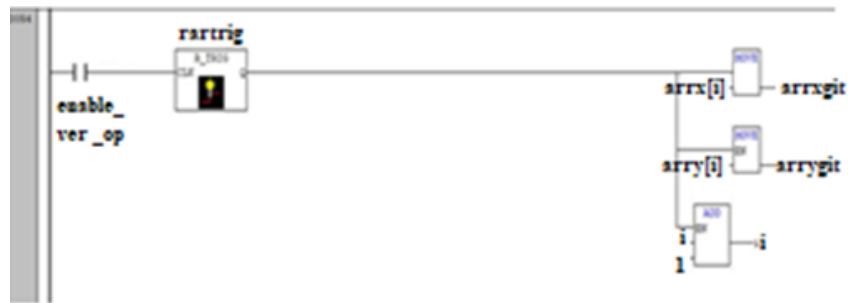

Figure 4. Go to the first coordinate

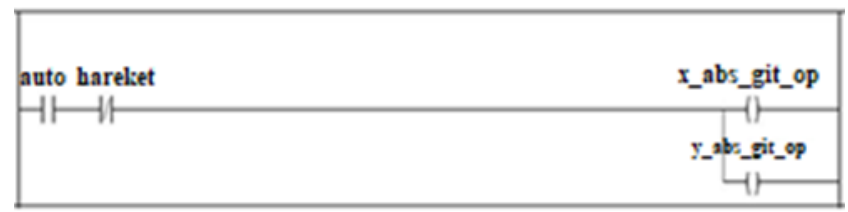

Figure 5. PLC block diagram 


\subsection{Image Processing}

In recent years, image processing studies have been widely used in many different fields (Priyanto et al. 2015; Senthilkumaran et al. 2016; Vishesh et al. 2017; Banafian et al. 2021). In this study, an image processing application was carried out on the Gantry Robot mechanism. With the 'Image Processing Toolbox' it contains, MATLAB has enabled the 'Image Processing' technique used in today's technology to be used very quickly and effectively. It is widely used in fields such as military, medicine, security systems, industrial systems, astronomy. In this study, the image was processed with the MATLAB software applied on the image that we took from the "uEye industrial type camera" produced by IDS Company and it was desired to obtain the necessary data that we would use on the PLC. The camera we used is shown below.

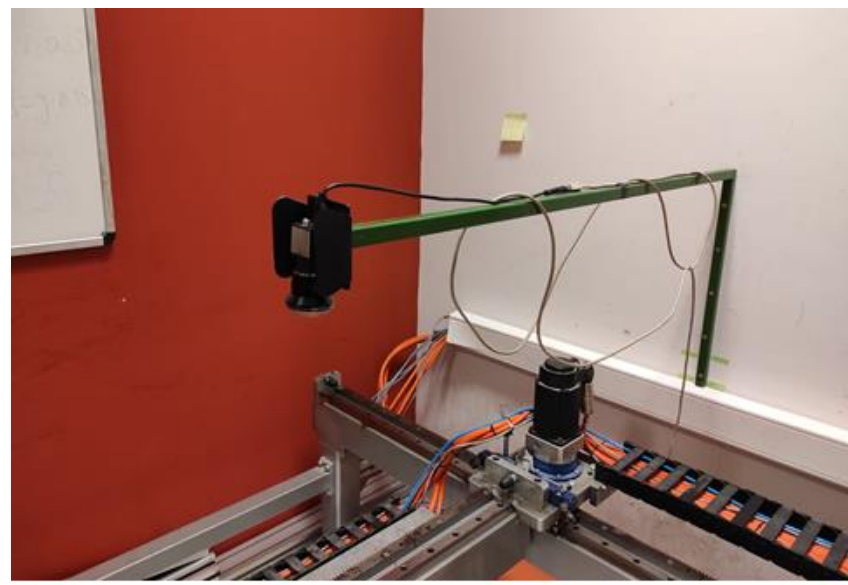

Figure 6. Image Processing Setup

In the image processing stage of the study, work is carried out on pixels. However, since the coordinate values we want to find are real-time, it is necessary to establish the pixel \& distance relationship between them. Our goal is to access the variable values that create this difference between them. First, the image is taken from the camera. Thus, it is aimed to reach the information according to which dimensions an image is taken from the camera should be synchronized. It looks like below.

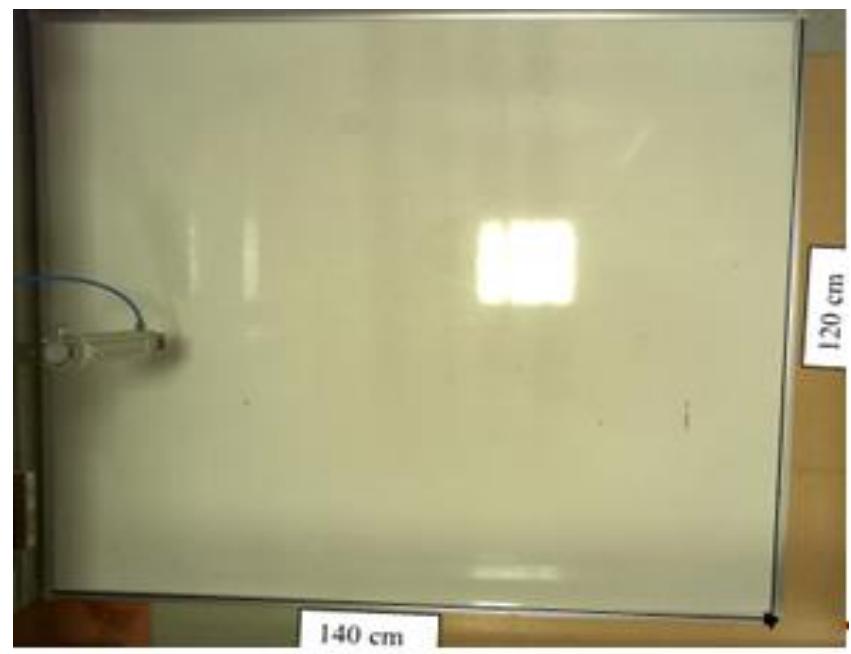

Figure 7. The maximum viewing angle of the image that can be taken with a camera
Next, the information we need to know is where the maximum and minimum points of the servo motors we control with PLC are. After obtaining the information about where these points are, images of the points are taken and a note is taken to which pixel values they correspond to. In Figure 7, the maximum and minimum points are marked.

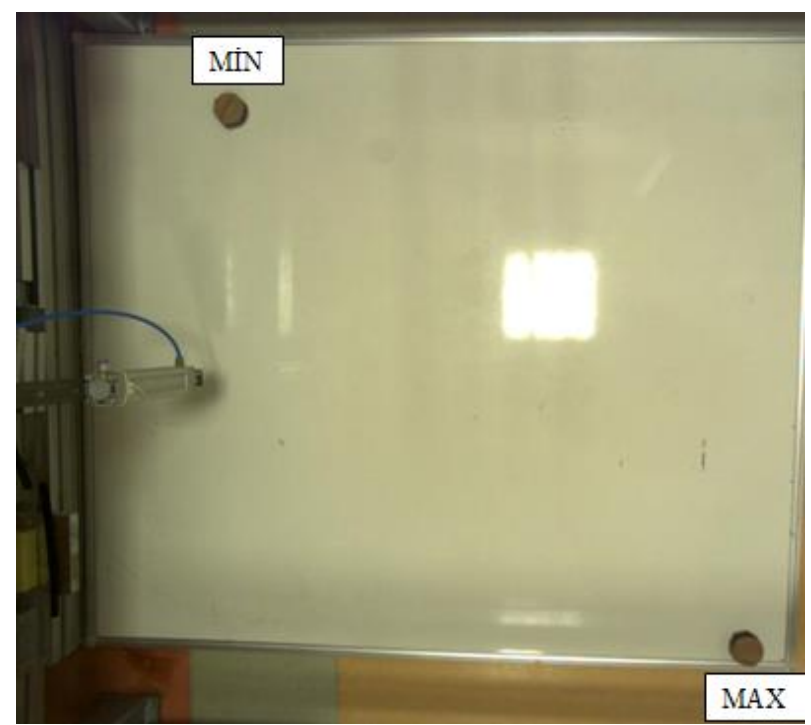

Figure 8. Regions corresponding to Min $(0,0)$ and Max $(10000000,10000000)$ points in the Cartesian system.

After the corresponding points are found, the Eq. (1) is used.

$$
\begin{aligned}
& f(x)=m\left(x-X_{i}\right) \\
& f(y)=m\left(y-Y_{i}\right)
\end{aligned}
$$

To solve these equations, we first define the $f(x)$ and $\mathrm{f}(\mathrm{y})$ values to be 1000000 , which is the maximum value reached by the servos.

Next, define the Xi and Yi values to the pixel values corresponding to the minimum points reached by the servos.

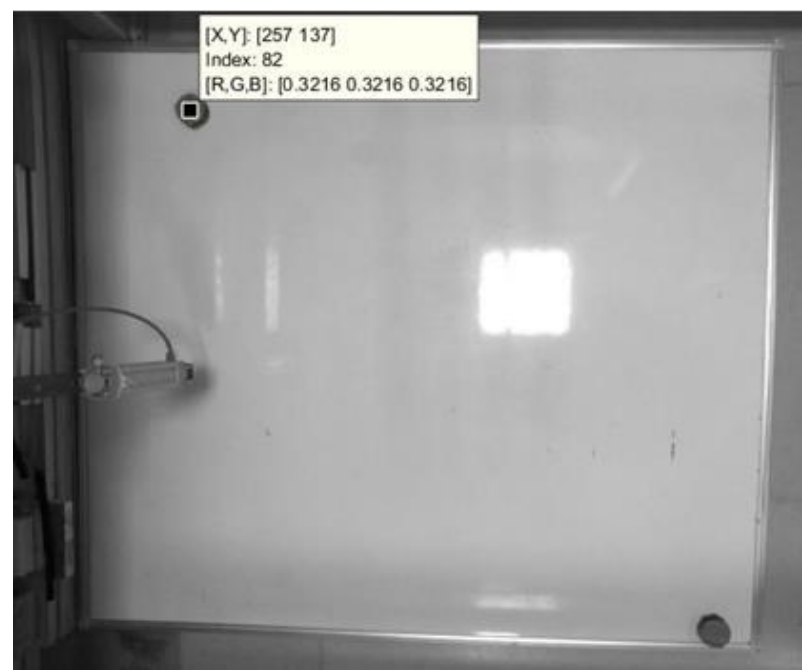

Figure 9. Pixel values corresponding to the point $(0,0)$ used on the machine are shown

As seen in Figure 8, the pixels corresponding to the minimum points obtained in the Cartesian plane are 257 for Xi value, For the Yi value, it is found as 137. The pixel 
locations obtained by moving the servos to any desired point are assigned to the $\mathrm{x}$ and $\mathrm{y}$ values. The values are assigned, the Eq. (2) is checked. As a result of the check, the following equation is obtained.

$$
\begin{aligned}
& f(x)=14836.79(x-257) \\
& f(y)=14136.91(y-137)
\end{aligned}
$$

With Eq. (2), it is aimed to reach the information of which coordinates the image taken by the cameras should reach in 'mm'. In these processes, the system was sent to random points and the results were tested. At the end of the results, it was obtained that the camera was synchronous.

First of all, the image taken from the camera is taken on MATLAB with the 'imread' command. The captured image is in RGB (Red-Green-Blue) color space. To facilitate image processing, the image should be converted to gray color space. If the image is not converted to the gray color space, separate operations will not have performed on the three-color domains. This causes processing to slow down. In the figures below, the image is in its original state and converted to gray color space on MATLAB.

In the continuation of the operations, the 'imfindcircles' function included in the 'Image Processing Toolbox' application of MATLAB is used. The 'imfindcircles' function is a function that finds the circular objects in the image between the entered radius values by applying Hough Transform. With the 'Edge Detection' algorithm, it has been tried to detect the edges of the objects in the image. Each pixel is searched for a circle that can be created at the coordinates of the accumulator array mentioned above. If the operation is positive, it calculates the center and radius of the circle. All the circular objects created are specified as the largest shape rounds in the Hough Transform space with the accumulator sequence. At the output of the operations, the $\mathrm{x}, \mathrm{y}$ coordinates, and radii of the circles are obtained. The received coordinate data is transferred to a matrix called 'center', which has the number of rows to which the number of rounds received and the number of two columns depend. Radius information, which is another information received, is transferred to an array named 'radicap' whose element number depends on the number of circles. In the figure below, the values rounded to integers with the 'round' operation are divided into different matrices one by one. Its purpose is to obtain the coordinates as a result of multiplying each coordinate with separate parameters during synchronization. The following image shows the relevant code block.

In the rest of the software, the 'viscircles' function was applied. The purpose of this function is to draw circles with certain centers and radius specified above, according to the entered values to determine which ones are on the image. The synchronization of the camera has been done in the above-mentioned topic. To apply the synchronization application function, the ' $\mathrm{x}$ ' and ' $y$ ' values of the received coordinates were separated from each other and assigned to other variables. Immediately after, the synchronization

process was applied to the variables and real-time coordinates were obtained and defined to "Koor1..N" variables (Kuncan et al. 2016; Kuncan and Kaplan 2016; Şengül et al. 2020; Alekseevic 2020; Belgacem et al. 2020).

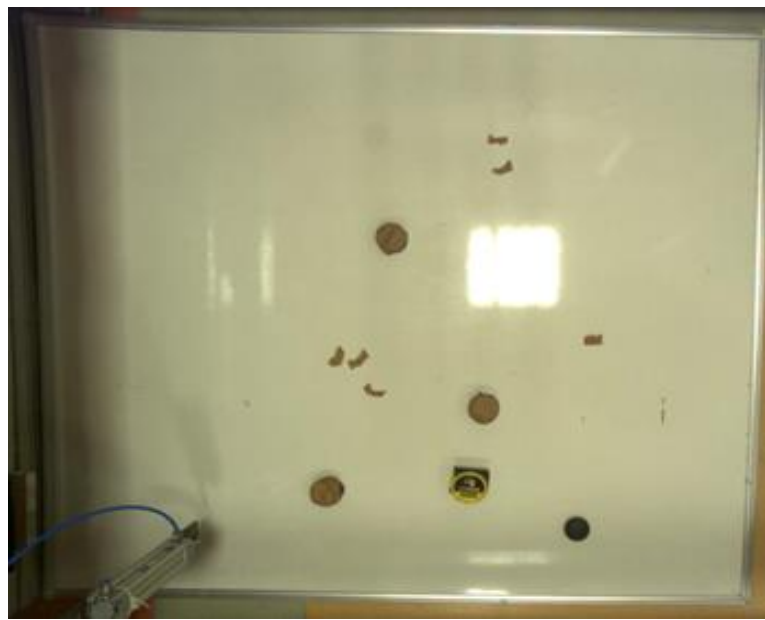

Figure 10. The maximum viewing angle of the image that can be taken with a camera

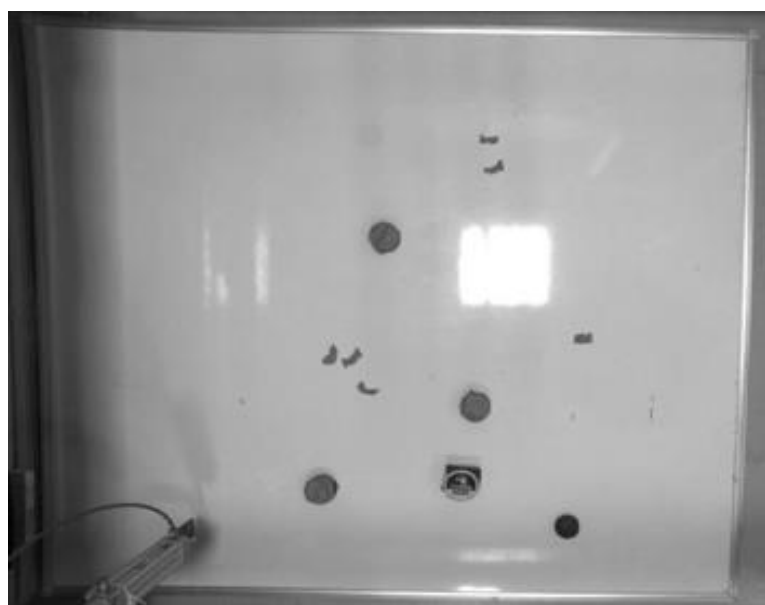

Figure 11. The maximum viewing angle of the image that can be taken with a camera

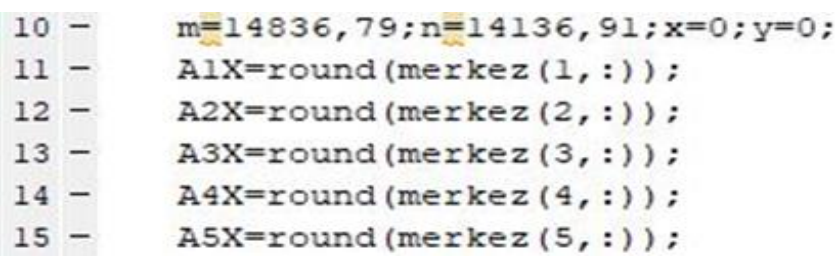

Figure 12. The process of assigning 'round' coordinate values rounded to integers with synchronization

\begin{tabular}{|c|c|}
\hline $27-$ & a. $2=\mathrm{A} .2 \mathrm{X}(2,2)$; \\
\hline $26-$ & $\mathrm{b} 2-\mathrm{A} 2 \mathrm{X}(2,2) \mathrm{z}$ \\
\hline $19-$ & $2.12=\cdot(\Delta .1-257) z$ \\
\hline $20-$ & $\mathrm{B} 11-\mathrm{n} *(\mathrm{~b} 1-137) z$ \\
\hline 21 & Koor2= (A22 B21 $\}$ z \\
\hline 22 & $\Delta 2-2.2 X(2,2) z$ \\
\hline 23 & $\mathrm{~b} 2-\mathrm{A} 2 \mathrm{X}(2,2) \mathrm{z}$ \\
\hline 24 & $2.22-=(0.2-257) z$ \\
\hline 25 & $B 22-\mathrm{n}^{*}(\mathrm{~b} 2-137) z$ \\
\hline 26 & Xoor2- $(222822):$ \\
\hline 27 & a $3-23 \times(2,2) z$ \\
\hline 20 & b $3-23 \times(2,2) z$ \\
\hline $29-$ & $A 33-m \cdot(a 3-257) z$ \\
\hline
\end{tabular}
parameters

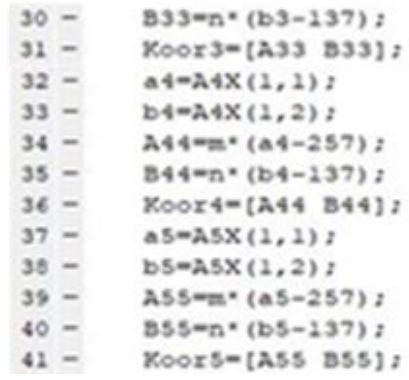

Figure 13. Applying the synchronization function to pixel coordinates and moving to real-time coordinates 


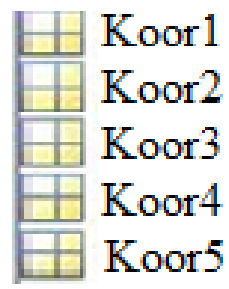

[3887032 2954424]

[2596300 8114064]

[5444812 8057520]

[5726696 6431880]

[7581196 8877408]

Figure 14. Obtained real-time coordinates

\section{REAL-TIME OPERATION OF THE SYSTEM}

At this stage of the study, the real-time operation of the system is explained. In the first part of this study, there is the stage of determining the coordinates of the objects with the proposed image processing method. In the second stage of the system, the coordinate values determined by image processing should be transmitted via software. According to the information received in the third stage, the servo motors have to perform the movement process correctly in the Gantry Robot system. As the last stage, there is the process of leaving the determined object to the determined place with the pneumatic equipment. Simultaneous transmission of all these stages is done via PLC. With the implementation of the autonomous system that has been built, the expected action is to transport the objects in the reached coordinates to different points on the Cartesian plane with a pneumatic system. For this action, there is a piston at the end of the servo moving on the ' $y$ ' axis. The task of this piston is to lift the object with the pneumatic system when the coordinate is reached and to leave it in place when the determined coordinate is reached.

The flowchart in Figure 15 consists of 4 separate columns. These columns represent 4 main operations.

The first column of the flow chart includes the description of the image processing phase. In this phase image will be taken by the camera and various functions will be applied to get the centers and coordinates.

The second column also shows that the coordinates obtained from image processing are assigned to the

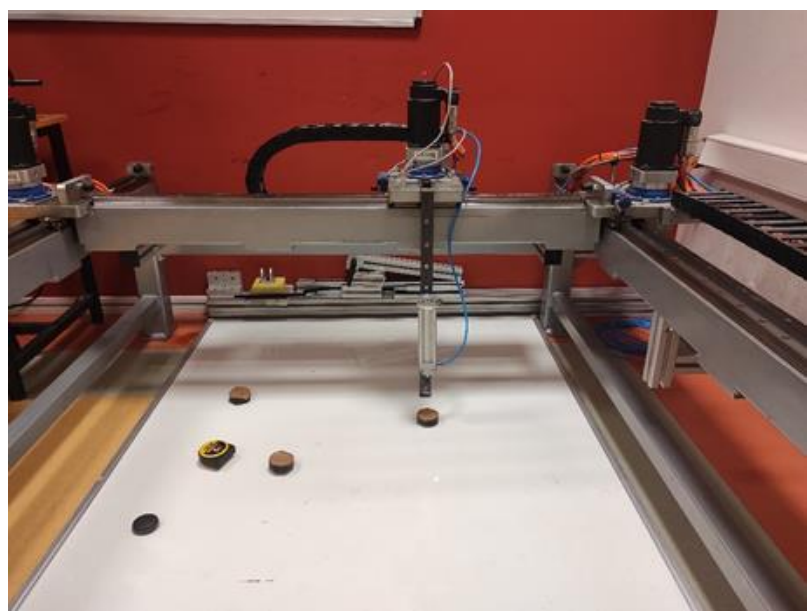

Figure 16. The system reaches the first coordinate received necessary sequences in the PLC. Movements of the servo motors that are controlled by PLC will be checked by 'DONE' bits to move synchronized as real-time coordinates given by it. If the synchronization process is successful, the transition to the next phase is achieved.

The third column of the chart includes the process of reaching the objects and lifting them with a vacuum and delivering them to the assembly coordinate.

The final column starts with the condition. The condition represents the final movement of the third column. If the last object has been lifted and delivered to the rally point, the mechanism will advance to the starting point. Otherwise, the system will repeat the third column until the last point will be reached.
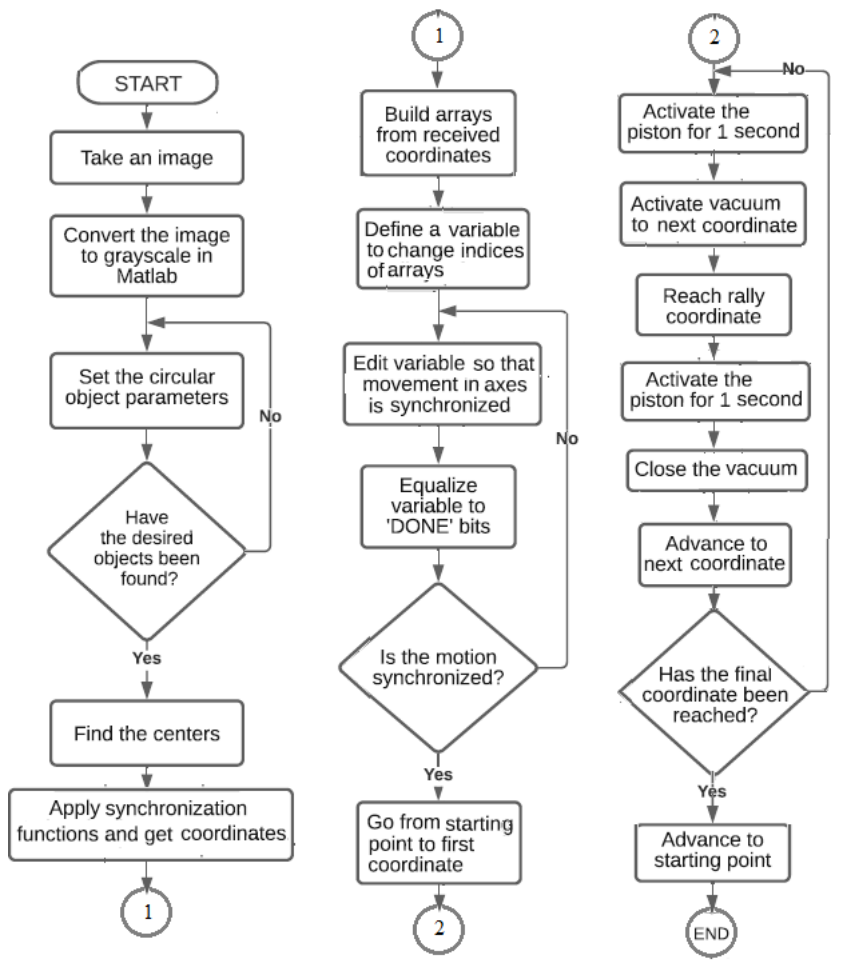

Figure 15. Flowchart of the system algorithm

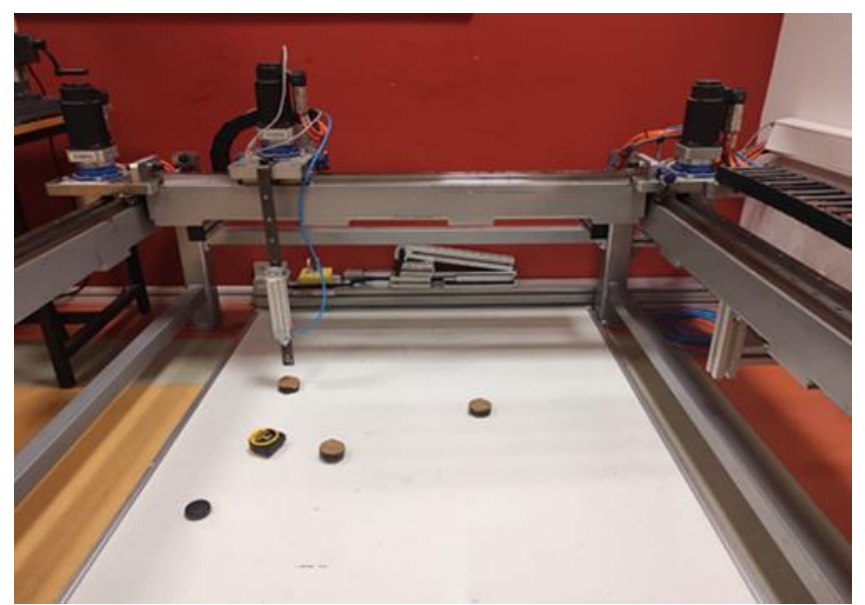

Figure 17. The system reaches the second coordinate received 


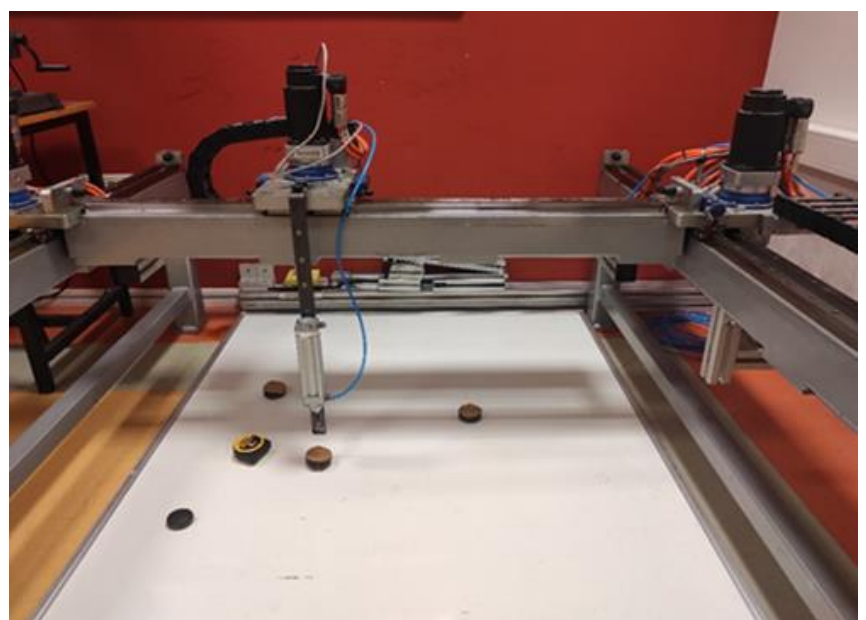

Figure 18. The system reaches the third coordinate received

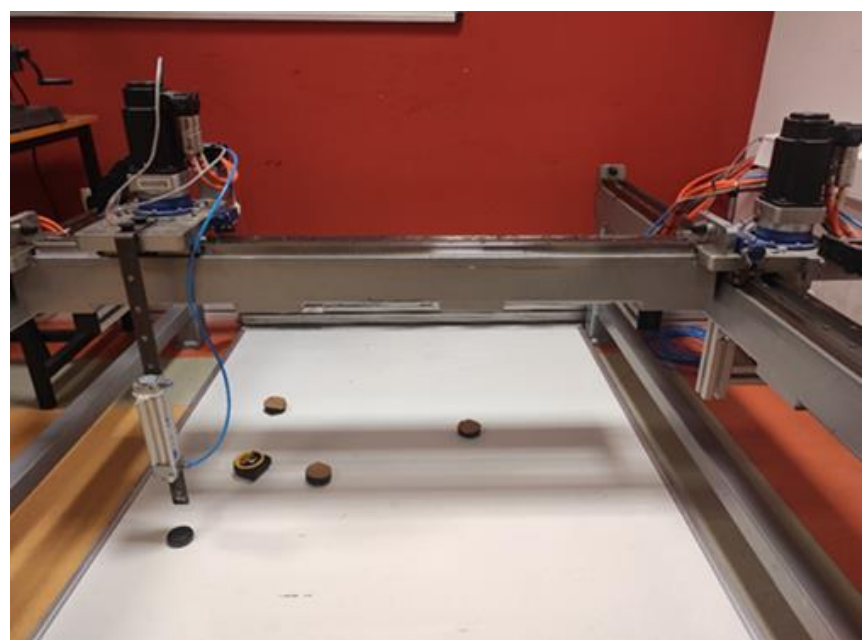

Figure 20. The system reaches the last coordinate received

\section{CONCLUSION and RESULTS}

In this study, it is aimed to create an autonomous system with Bosch-Rexroth PLC, in which the image was taken with an industrial camera, image processing methods in the MATLAB environment, and servo motors and drivers are controlled on the Cartesian machine. With this system, the coordinate data obtained by using image processing methods using the MATLAB program and the coordinates targeted by the PLC were transmitted to the system autonomously. Afterward, a pneumatic system was established and it was aimed to transport the objects to different points. During the study, the results obtained by using the image processing functions, the working logic of the servo motors, and the programming techniques of the PLC systems were made on the setup.

The coordinates of the objects are determined by using image processing methods, and these coordinates are sent to the desired point by using PLC in the Gantry Robot system. A pneumatic system was designed on the $y$-axis of the Gantry Robot system and the designed system was mounted. Thanks to this pneumatic system integrated into the Gantry Robot system, the objects in the determined coordinates were transported to another coordinate with the help of air. The performance of the system was evaluated by repeating

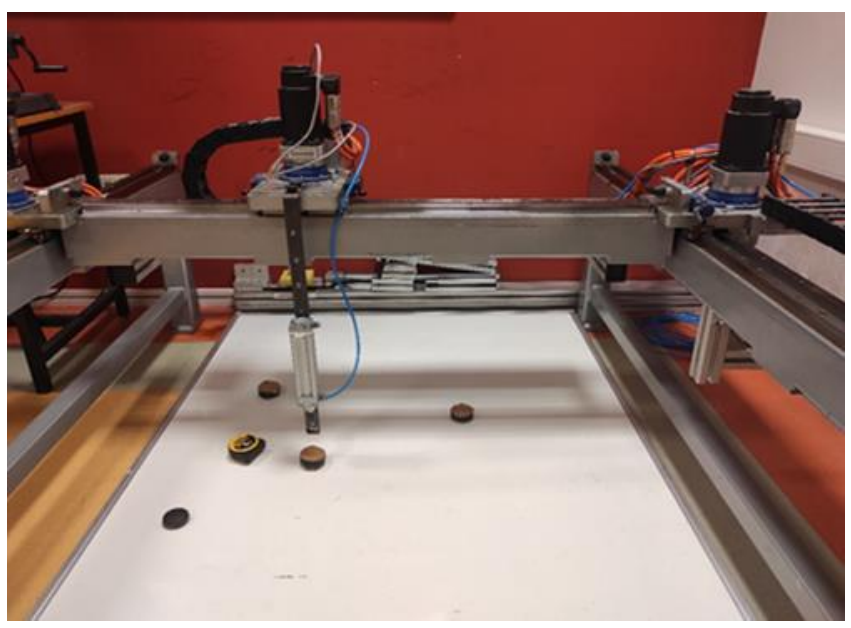

Figure 19. The system reaches the fourth coordinate received

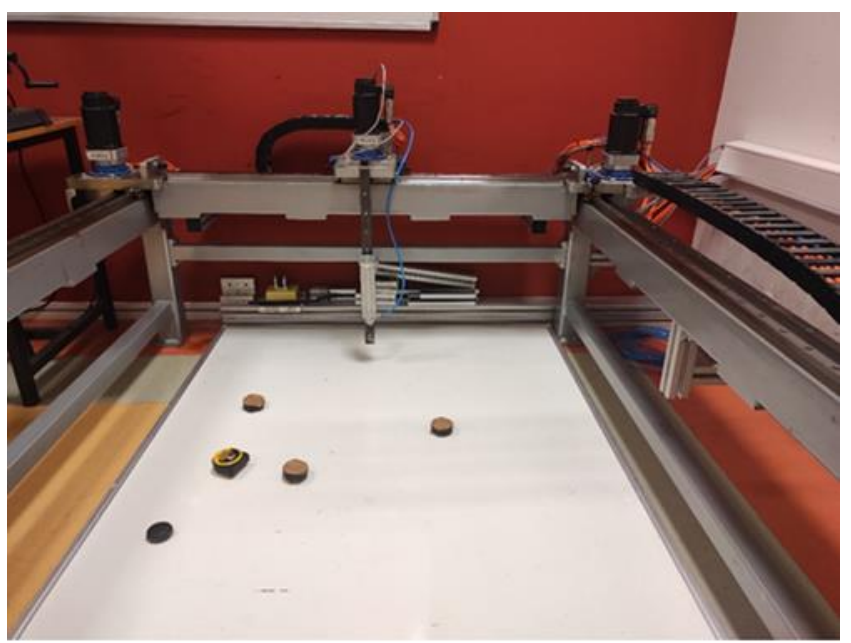

Figure 21. System returns to the initial position

the study on the setup developed for many test applications for different conditions. As a result of the test studies, it has been observed that both the image processing method and the system work simultaneously with high accuracy.

It is known that the Gantry Robot system works in different conditions in many industrial applications and gains high accuracy results to users as their desires. Technological improvements of robotics demand high accuracy with ergonomic designs. This kind of PLC system also can be developed in many different industrial areas. The algorithm can be upgraded or downgraded to wanted spectrums. Thanks to the study, it is thought to be a real-time study that has the potential to be used in many different studies.

\section{Author contributions}

Fatma Kuncan: Conceptualization, Methodology, Software, Writing-Reviewing and Editing. Sitkı Öztürk: Data curation, Writing-Original draft preparation, Software, Validation. Fatih Han Keleş: Visualization, Investigation, Writing-Reviewing and Editing. 


\section{Conflicts of interest}

The authors declare no conflicts of interest.

\section{REFERENCES}

Alekseevic N R (2020). The investigating algorithms of crack position determination based on imagery processing and photogrammetry methods.

Bakır A, Güney Ö F, Kuncan M, Ertunç H M (2012). 3 Eksenli Robot Mekanizmasına Monte Edilmiş Bir Kamera Vasıtasıyla Farklı Rotasyon ve Boyutlardaki Geometrik Cisimlerin Tanımlanarak Vakum Tutucu ile Ayrılması. Otomatik Kontrol Ulusal Toplantısı, Niğde, Turkey, 606-609.

Banafian N, Fesharakifard R \& Menhaj M B (2021). Precise seam tracking in robotic welding by an improved image processing approach. The International Journal of Advanced Manufacturing Technology, 114(1), 251-270.

Belgacem I, Jonniaux G \& Schmidt F (2020). Image processing for precise geometry determination. Planetary and Space Science, 193, 105081.

Çubukçu A, Kuncan M, İmren M, Erol F, Ertunç H M, Öztürk S \& Kaplan K (2015). Görüntü ișleme ile 3 eksenli robot mekanizması üzerinde nesne ayırt edilmesi ve siralanması. Otomatik Kontrol Ulusal Toplantısı. 637-641.

Horoz E, Öten H F, Kuncan M \& Ertunç H M (2013). Kamera Yardımı ile Ayırt Edilen ve Tanımlanan Cisimlerin 3 Eksenli Robot Mekanizması ile Tașınması. Otomatik Kontrol Ulusal Toplantısı, Malatya, Turkey, 1236-1240.

Hu X, Deng X \& Zhao Q (2021). A gantry robot system for cutting single Y-shaped welding grooves on plane workpieces. Proceedings of the Institution of Mechanical Engineers, Part E: Journal of Process Mechanical Engineering, 235(2), 321-331.
Jose A \& Udupa G (2021). Gantry robot system for preventing drowning accidents in swimming pools. Materials Today: Proceedings, 46, 4975-4981.

Kuncan M, Kaplan K, Acar F, Kundakçi I M \& Ertunç H M (2016). Fuzzy logic based ball on plate balancing system real time control by image processing. International Journal of Natural and Engineering Sciences, 10(3), 28-32.

Köse İ, Öztürk S, Kuncan M (2019). Pantography application with real-time PLC based on image processing in gantry robot system. European Journal of Technique (EJT), 9(2), 219-229.

Kuncan M \& Kaplan K (2016). POSITION DETERMINATION BY USING IMAGE PROCESSING METHOD IN INVERTED PENDULUM. Middle East Journal, 1(2).

Senthilkumaran N, Vaithegi S, (2016). Image Segmentation by Using Thresholding Techniques for Medical Images, Computer Science \& Engineering: An International Journal (CSEIJ), 6(1), February 2016.

Şengül Ö, Öztürk S \& Kuncan M (2020). Color based object separation in conveyor belt using PLC. Avrupa Bilim ve Teknoloji Dergisi, (18), 401-412.

Priyanto H \& Miftahuddin Z (2015). Color-Texture Based Object Tracking Using HSV Color Space and Local Binary Pattern, International Journal on Electrical Engineering and Informatics - 7(2), June 2015.

Vishesh G, Tarun J, Sahil S \& Silica K (2017). Specific Color Detection in Images using RGB Modelling in MATLAB, International Journal of Computer Applications (0975 - 8887), 161(8), March 2017. 